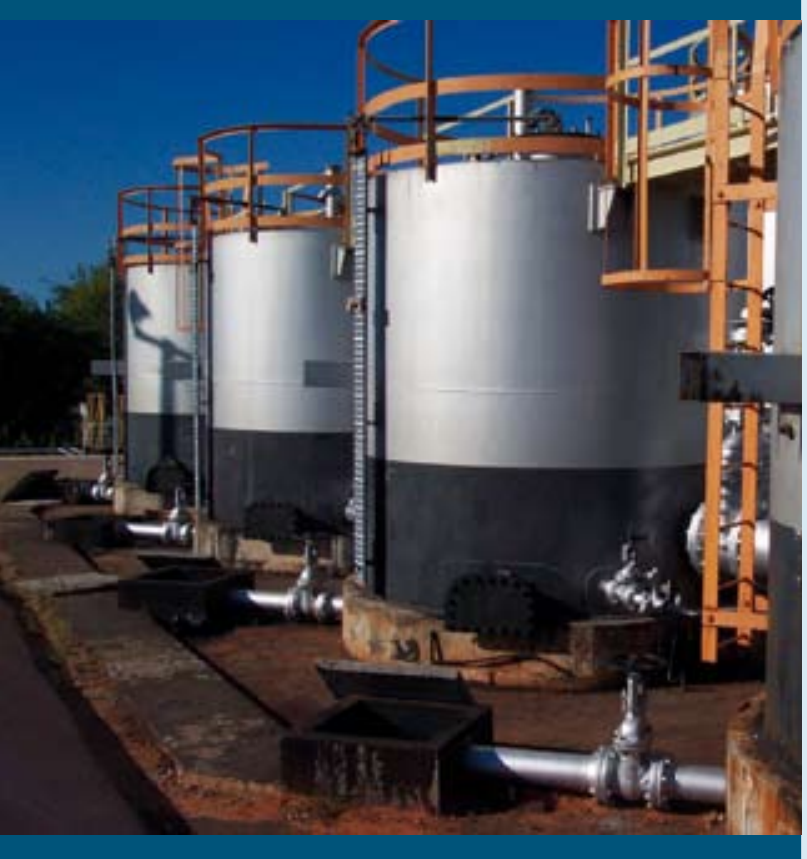

\title{
Educação tecnológica para a indústria brasileira
}

ALBERTO BORGES DE ARAUJO

PALAVRAS-CHAVE:

Educação; Indústria; Graduação; Tecnologia.

\section{KEY WORDS:}

Education; Industry; Undergraduate Education; Technology. 


\section{Resumo}

O objetivo deste estudo é subsidiar o entendimento sobre o contexto da educação tecnológica no Brasil, representada pelos cursos de graduação e pós-graduação destinados à qualificação profissional, indispensáveis ao desenvolvimento da indústria do país.

Por muitos anos foram adotados sistemas diferenciados de educação profissional técnica, voltados para os ofícios, e de educação mais acadêmica. O SENAI, que se mantém em permanente sintonia com instituições ligadas à educação profissional de todo o mundo, trouxe de diversos países exemplos valiosos de universidades tecnológicas e vem realizando esforços junto ao Ministério da Educação (MEC) para apoio à pesquisa, a acordos bilaterais e à pós-graduação em diversas áreas profissionais, para garantir uma educação superior de qualidade e adequada às necessidades do sistema produtivo.

\section{Abstract}

This study aims at contributing to the understanding of the context of technological education in Brazil, more specifically as regards undergraduate and postgraduate programs for professional qualification, which are essential for the development of Brazil's industry.

For many years different systems were adopted for, on the one hand, technical and technological education and training, targeting trades and occupations, and, on the other hand, academic education. More recently, in line with developments in technical and vocational education institutions worldwide, SENAI is introducing successful models for the establishment of technological universities. It is also collaborating with the Ministry of Education (MEC) in the design of policies to support research and postgraduate programs in several technological areas, as well as in the signing of bilateral agreements, with a view to ensuring the provision quality higher learning services that meets the needs of the country's productive system. 


\section{Introdução}

O objetivo deste trabalho é construir um entendimento integral da educação profissional e tecnológica naquilo que ela representa de estratégico para a indústria brasileira.

Para alcançar esse objetivo, trabalha-se com uma visão diacrônica conceitual e operativo-evolutiva, ensejando uma leitura de conjunto de um processo histórico que tem sua gênese em 22 de janeiro de 1942, com o Decreto-lei no 4.048, instituto legal de criação do Serviço Nacional de Aprendizagem Industrial - SENAI.

Ao longo desse período, o mundo sofreu uma extraordinária metamorfose em cujo bojo a visão de ciência como conhecimento puro, divorciado da sociedade, perdeu o sentido, assumindo um caráter de ciência como força produtiva, sob o influxo de estruturas sociais e produtivas que modelam e dirigem seu curso, seus métodos e os resultados que produz.

A conseqüência desse processo tem sido a modelagem de novas formas de organização do trabalho e de grandes mudanças tecnológicas ocorridas nos últimos anos, que transformaram as formas de produção, até então caracterizadas como atividades repetitivas e com reduzido conhecimento agregado, fazendo eclodir processos com crescentes níveis de complexidade tecnológica. Por essa razão é que, no presente trabalho, estão detalhadas as mudanças demandadas pela indústria, para manter-se competitiva diante do cenário atual e frente ao qual os cursos de tecnologia são uma resposta efetiva, especialmente como formação profissional para uma rápida inserção no mercado de trabalho, ou para aqueles que, estando já na indústria, necessitam de qualificação para obter a desejada progressão funcional.

É fato que o desenvolvimento tecnológico e o uso de tecnologias exigem, crescentemente, o aporte de conhecimentos científicos e a gestão do aparato científico correspondente. Como esse nível de conhecimento hospeda-se nos centros de pesquisa e na educação superior, é imperiosa a iniciativa do setor produtivo de recorrer a níveis cada vez mais elevados de formação da classe trabalhadora. A engenharia de realinhamento dos diferentes esquemas de formação profissional constitui um enorme desafio para um sistema como o SENAI, com mais de 700 unidades operacionais, nos
É fato que o desenvolvimento

tecnológico e o uso de tecnologias

exigem, crescentemente, 0 aporte de

conhecimentos científicos e a gestão

do aparato científico correspondente.

27 estados brasileiros, formando, atualmente, $2 \mathrm{mi}-$ Ihões de profissionais por ano.

Ao longo de sua trajetória, o SENAI sempre adequou a sua ação formativa aos novos perfis exigidos pelo mercado, seja revendo diretrizes, programas, projetos e ações, seja intensificando a sua presença em ambientes tecnológicos. A decisão do SENAI de implantar cursos de graduação em tecnologia reflete a preocupação da instituição em formar profissionais cada vez mais qualificados e especializados.

O objetivo deste trabalho é, portanto, aclarar o entendimento sobre o significado da educação profissional para a indústria brasileira, em nível tecnológico, apresentando rotas consideradas indispensáveis ao desenvolvimento industrial do país. Como esclarece o Presidente da Confederação Nacional da Indústria, Armando Monteiro Neto, "O desenvolvimento socioeconômico nacional estará relacionado, em grande parte, ao desempenho satisfatório dos vários segmentos do setor industrial, que, por sua vez, dependem substancialmente da inovação e do desenvolvimento tecnológico para elevar a produtividade e a competitividade (...). Para tanto, prossegue, (...) é fundamental (...) elevar de forma substancial a pesquisa, a geração de inovação, o desenvolvimento tecnológico e a formação de pessoal qualificado para atuar em áreas técnicas industriais" (2003, p. 373). Essa idéia está reforçada no conjunto dos eixos norteadores do Relatório Faure, em cujo desdobramento estão fixados princípios no que diz respeito à preparação para o trabalho, como: a educação deve formar não apenas para um ofício, como também preparar os jovens para se adaptarem a trabalhos diferentes, à medida que evoluam as formas de produção (Unesco, 2000, p. 5). 


\section{A estrutura da educação no Brasil}

A Lei de Diretrizes e Bases da Educação Nacional (Lei no 9.394/96 - LDB) determina que "a educação escolar deverá vincular-se ao mundo do trabalho e à prática so-

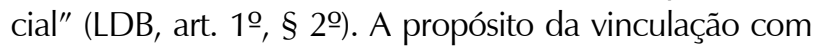
o mundo do trabalho e à prática social, a LDB reservou, em seu Título V, o Capítulo III, com os artigos 39 a 42 para organizar a educação profissional.

Em seu art. 39, a LDB afirma que a educação profissional, integrada às diferentes formas de educação, ao trabalho, à ciência e à tecnologia conduz ao permanente desenvolvimento de aptidões para a vida produtiva. Por fim, arremata, em seu art. 40, que a educação profissional será desenvolvida em articulação com o ensino regular ou por diferentes estratégias de educação continuada em instituições especializadas ou no ambiente de trabalho.

A relação educação/trabalho, marcantemente presente na LDB, destaca a preocupação do legislador em estabelecer graus de formalização na estrutura da educação brasileira, de tal sorte que o conjunto dos serviços e atividades educacionais, como anota recente documento do IPEA (2006, p. 15), possa contribuir efetivamente para a elevação da performance do cidadão brasileiro como ator social e como protagonista ativo do desenvolvimento nacional. Esses serviços e atividades se distribuem em uma imensa rede de instituições que operam níveis de ensino e modalidades educativas de acordo com a seguinte estrutura:

\section{Figura 1. Diagrama da estrutura da educação no Brasil - MEC'}

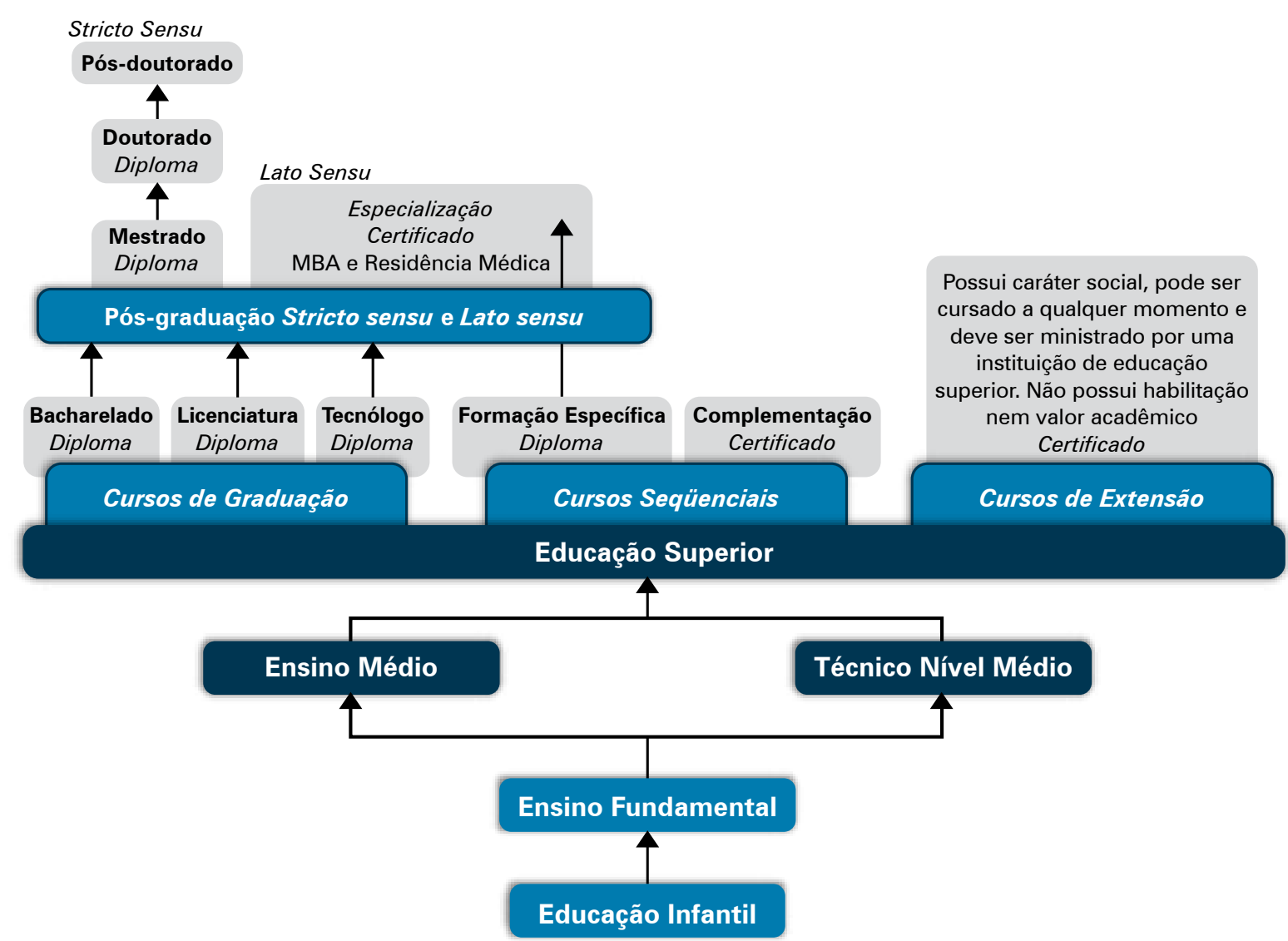

1. Disponível no sítio eletrônico do Ministério da Educação: www.mec.gov.br. 
A educação escolar no Brasil, segundo a LDB, estrutura-se em níveis - educação básica e educação superior.

A educação básica, que "tem por finalidades desenvolver o educando, assegurar-lhe a formação comum indispensável para o exercício da cidadania e fornecerIhe meios para progredir no trabalho e em estudos posteriores" (art. 22, da LDB), compreende três etapas:

- Educação infantil - destinada às crianças até seis anos de idade, podendo organizar-se, em creches, para crianças até três anos, e pré-escolas, para as de quatro a seis anos. Constitui responsabilidade básica dos municípios;

- Ensino fundamental - obrigatório e gratuito nas escolas públicas, com duração de nove anos, para alunos dos seis aos quatorze anos de idade. Constitui responsabilidade comum dos municípios e dos estados federados;

- Ensino médio - etapa final da educação básica, com duração mínima de três anos, para alunos dos quinze aos dezessete anos de idade. Relaciona-se com a educação profissional técnica de nível médio, de forma independente e articulada, conduzindo obrigatoriamente à preparação geral para o trabalho e facultativamente à habilitação profissional (técnico de nível médio). Constitui responsabilidade básica dos estados federados.

A educação superior tem por finalidade (art. 43, da LDB):

I. estimular a criação cultural e o desenvolvimento do espírito científico e do pensamento reflexivo;

II. formar diplomados nas diferentes áreas de conhecimento, aptos para a inserção em setores profissionais e para a participação no desenvolvimento da sociedade brasileira, e colaborar na sua formação contínua;

III. incentivar o trabalho de pesquisa e investigação científica, visando ao desenvolvimento da ciência e da tecnologia e da criação e difusão da cultura e, desse modo, desenvolver o entendimento do homem e do meio em que vive;

IV. promover a divulgação de conhecimentos culturais, científicos e técnicos que constituem patrimônio da humanidade e comunicar o saber através do ensino, de publicações ou de outras formas de comunicação;
V. suscitar o desejo permanente de aperfeiçoamento cultural e profissional e possibilitar a correspondente concretização, integrando os conhecimentos que vão sendo adquiridos numa estrutura intelectual sistematizadora do conhecimento de cada geração;

VI. estimular o conhecimento dos problemas do mundo presente, em particular os nacionais e regionais, prestar serviços especializados à comunidade e estabelecer com esta uma relação de reciprocidade;

VII. promover a extensão, aberta à participação da população, visando à difusão das conquistas e benefícios resultantes da criação cultural e da pesquisa científica e tecnológica geradas na instituição".

Em sua organização, a educação superior abrange os seguintes cursos e programas, abertos aos concluintes do ensino médio ou equivalente, com duração variável, de acordo com as suas características e complexidade:

- Cursos seqüenciais - cursos de nível superior por campos de saber de diferentes níveis de abrangência. Compreendem cursos superiores de formação específica com destinação coletiva, conduzindo a diploma e habilitando seu portador a cursar regularmente cursos de especialização de acordo com a legislação vigente, e cursos superiores de complementação de estudos com destinação individual ou coletiva, conduzindo a certificado.

- Cursos de graduação - abertos a candidatos que tenham concluído o ensino médio ou equivalente e tenham sido classificados em processo seletivo. Compreendem cursos de bacharelado, licenciatura e tecnologia, com duração diversa e conferindo diploma.

- Cursos de pós-graduação - compreendem cursos e programas de mestrado, doutorado, especialização, aperfeiçoamento e outros, abertos a candidatos diplomados em cursos de graduação e que atendam às exigências das instituições de ensino. Denominam-se como pós-graduação lato sensu e stricto sensu. Como cursos de pósgraduação lato sensu, estão os cursos de especialização, os designados como MBA e os denominados Programas de Residência Médica, levando à certificação de seus concluintes. Como cursos de pós-graduação stricto sensu, estão o mestrado e o doutorado, conduzindo à diplomação. 
- Cursos de extensão - possuem caráter social, conferindo certificado, não tendo valor acadêmico.

São modalidades da educação escolar no Brasil a educação de jovens e adultos, a educação especial e a educação profissional, sendo que esta última perpassa todos os níveis e modalidades da educação nacional.

- Educação de jovens e adultos - destinada àqueles que não tiveram acesso ou continuidade de estudos no ensino fundamental e médio na idade própria.

- Educação especial - oferecida, preferencialmente, na rede regular de ensino, para educandos que apresentem necessidades educacionais especiais.

- Educação profissional - que, integrada às diferentes formas de educação, ao trabalho, à ciência e à tecnologia, conduz ao permanente desenvolvimento de aptidões para a vida produtiva. Destina-se ao aluno matriculado ou egresso do ensino fundamental, médio e superior, bem como ao trabalhador em geral, jovem ou adulto.

Na década de 1950, o SENAI, respondendo à demanda do setor

têxtil, ingressou no nível técnico da educação profissional. Portanto, 0 primeiro curso técnico oferecido pela instituição foi para a área têxtil.
A educação profissional, regulamentada pelo Decreto $n^{\circ} 5.154 / 2004$, estrutura-se em:

- Formação inicial e continuada de trabalhadores - oferecida em todos os níveis de escolaridade, inclui a capacitação, o aperfeiçoamento, a especialização e a atualização, podendo ser ofertada segundo itinerários formativos, visando ao desenvolvimento de aptidões para a vida social.

- Educação profissional técnica de nível médio - oferecida em articulação com o ensino médio, podendo ser integrada, concomitante ou subseqüente ao ensino médio.

- Educação profissional tecnológica de graduação e de pós-graduação - regida pelas normas da educação superior e oferecida aos egressos do ensino médio e superior, respectivamente.

- O Decreto-lei no 4.048/1942 estabelece como missão primordial do SENAI oferecer aprendizagem, sem excluir a possibilidade de outras formas e níveis de atuação contidos na abrangente expressão "ensino de continuação".

Na década de 1950, o SENAI, respondendo à demanda do setor têxtil, ingressou no nível técnico da educação profissional. Portanto, o primeiro curso técnico oferecido pela instituição foi para a área têxtil, na Escola Técnica da Indústria Química e Têxtil (ETIQT), atual CETIQT, no Rio de Janeiro, ligada diretamente, como é até hoje, ao Departamento Nacional. A partir daí, mediante demanda dos setores de cerâmica, fundição, curtimento, calçados, artes gráficas e de plástico, foram sendo implantados novos cursos técnicos em diferentes regiões do país, onde a demanda ocorria. A implantação dos cursos técnicos pelo SENAI passou a ocorrer acompanhando ou precedendo a presença ou ampliação de diferentes segmentos industriais, especialmente nas áreas de metal-mecânica, eletroeletrônica e construção civil. Outro fator determinante para a criação dos cursos técnicos do SENAI foi a necessidade de absorção e transferência de novas tecno- 


\section{Embora o foco da missão fosse sempre a aprendizagem industrial e a qualificação profissional básica de trabalhadores, a instituição tratou a educação profissional em sentido amplo.}

logias industriais. Exemplo disso foi a criação dos cursos técnicos de mecânica de precisão, robótica, usinagem a $\mathrm{CNC}$, instrumentação, mecatrônica, informática industrial e outros, instalados principalmente nos estados mais industrializados.

Assim, a missão institucional, sua flexibilidade organizacional e as demandas do mundo produtivo determinaram a oferta de cursos técnicos industriais pelo SENAI. Embora o foco da missão fosse sempre a aprendizagem industrial e a qualificação profissional básica de trabalhadores, a instituição tratou a educação profissional em sentido amplo. A agilidade da gestão do SENAl é de tal forma efetiva que permite a diversificação e ampliação das formas de atuação, segundo necessidades emergentes da indústria e da sociedade.

Ao longo de 65 anos, o SENAI construiu uma bemsucedida experiência de formação inicial e continuada, além da formação técnica de nível médio. Foi essa experiência que the possibilitou um contexto de condições potencialmente convergentes, para elevar o padrão de oferta de seus cursos através da disponibilização de serviços educacionais formais mais avançados, em consonância com as crescentes exigências da indústria por trabalhadores cada vez mais capacitados.

Em 1987, o SENAI ingressou na educação superior. O Centro de Tecnologia da Indústria Química e Têxtil (CETIQT), em atendimento à intensa demanda das empresas industriais, passou a desenvolver cursos de engenharia têxtil, inicialmente em parceria com a Universidade do Estado do Rio de Janeiro - UERJ, e, posteriormente, de forma autônoma. Daí por diante, a instituição passou a responder às demandas dos diversos segmentos industriais, implantando cursos de graduação em tecnologia, desde que não existissem cursos superiores similares na região, ou em razão da oferta insuficiente para as necessidades da indústria nacional.
Nessa perspectiva evolutiva, a Confederação Nacional da Indústria coordenou, em 2006, a elaboração de um conjunto de propostas, sob o nome de programa Inova Engenharia, com o propósito de reunir recomendações para a modernização da educação em engenharia no Brasil e para que o país possa retomar o crescimento de forma sustentável. O documento recomenda que a ampliação das vagas deve ser norteada por estratégias de desenvolvimento regional, com prioridade para as regiões Norte, Nordeste e Centro-Oeste, e para as áreas de ciências exatas, engenharias e formação de tecnólogos; sempre muito articulado com o setor empresarial, para promover uma formação voltada às necessidades do mercado, à transformação de conhecimento em riqueza, com foco prioritário nos setores apontados como estratégicos pela política tecnológica, industrial e de comércio exterior do país.

Para aprofundar os níveis de integração e contextualização, o programa Inova Engenharia recomenda, ainda, a conjugação entre as chamadas atividades teóricas e práticas que habilitam o futuro profissional para intervir na realidade, dominando suas nuanças por meio de atividades simuladas, como exercícios, trabalhos, estudos de caso, práticas raramente associadas aos conteúdos teóricos dos cursos.

\section{0 caminho indicado pelo Mapa Estratégico da Indústria}

Ao elaborar o Mapa Estratégico da Indústria para o período 2007 - 2015, o Fórum Nacional da Indústria, numa iniciativa da Confederação Nacional da Indústria, estabeleceu dentre os objetivos estratégicos no campo da educação: 


\section{Figura 2 - Mapa Estratégico da Indústria ${ }^{2}$}

- Sociedade

- Trabalhadores

- Empresários

- Governo
Crescimento

Econômico

Posicionamento
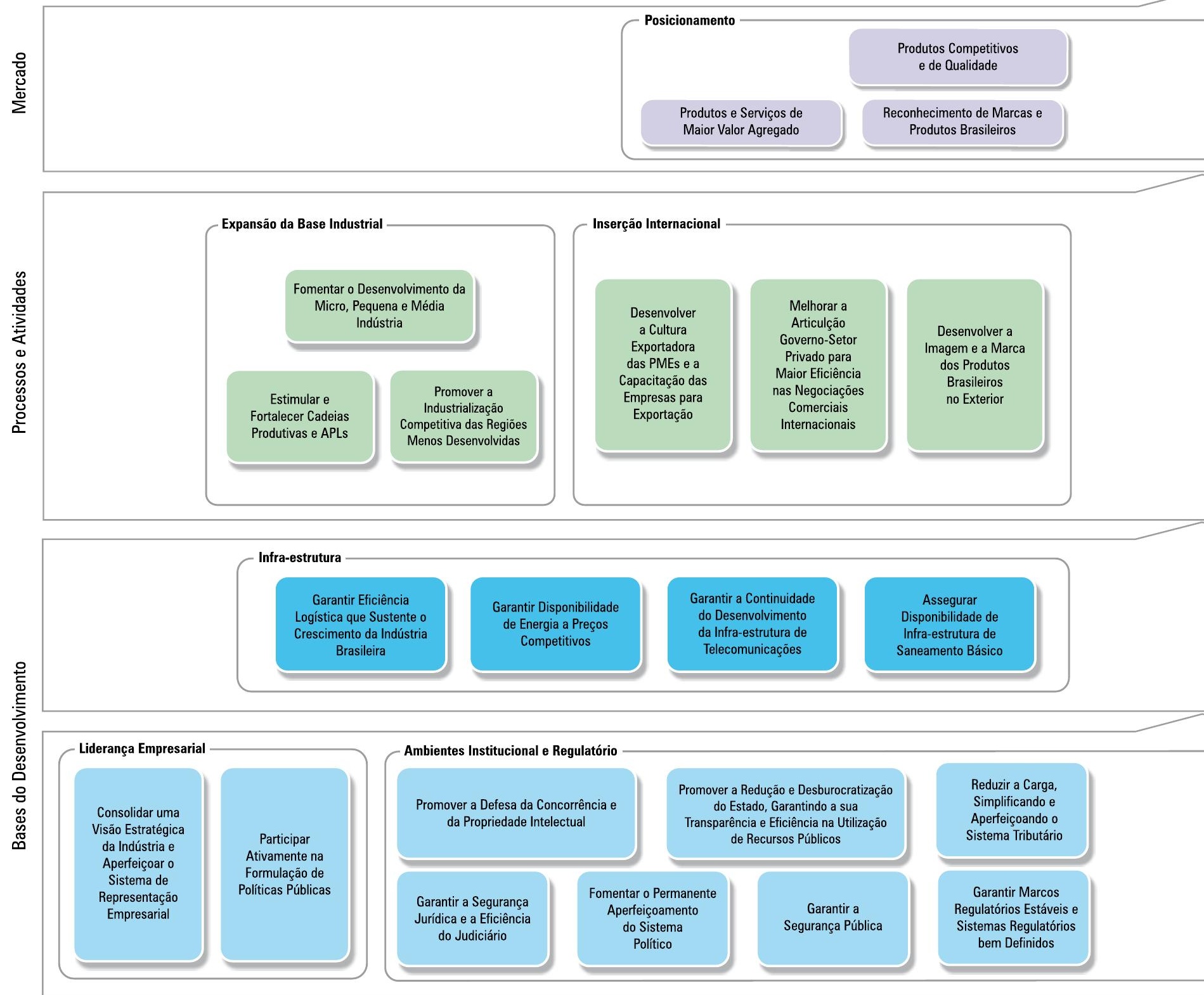


\section{Garantir uma educação superior de qualidade e adequada às necessidades da economia do conhecimento $\mathrm{e}$ do sistema produtivo}

Segundo os industriais, o ensino superior brasileiro precisa atender às necessidades da economia do conhecimento e do desenvolvimento industrial do país, promovendo a oferta de novos talentos e competências. Os conteúdos acadêmicos devem ser reformados para incluir habilidades e novas competências (capacidade de comunicação, resolução de problemas, trabalho em equipe) e orientados à utilização prática dos conhecimentos teóricos, favorecendo a empregabilidade dos profissionais formados. Entre outros desafios, a reforma do sistema de educação superior deve garantir a instituição de um sistema adequado de avaliação das instituições de ensino superior, a ampliação da oferta de ensino superior na área tecnológica e o desenvolvimento de pesquisa básica e aplicada com padrão internacional.

\section{Fortalecer a educação profissional e tecnológica}

Ao construírem o Mapa da Indústria, os empresários industriais brasileiros também consideraram que a educação profissional e tecnológica constitui um suporte estratégico para a sustentabilidade e competitividade da indústria brasileira.

Reafirmam os empresários industriais brasileiros que é fundamental garantir o atendimento das demandas de formação inicial e continuada de trabalhadores, de educação profissional técnica de nível médio, sem descuidar da educação tecnológica, de graduação e pósgraduação. Enfatizam, também, que os problemas da educação profissional e tecnológica enquadram-se, em grande parte, na ausência da prospecção adequada de sua demanda, na flexibilização da oferta formativa e no reconhecimento de competências dos trabalhadores.

Assim, o SENAI passou a desenvolver o planejamento de suas atividades de educação profissional com estudos de prospecção, identificação de demandas e definição de perfis profissionais e itinerários formativos. São metodologias próprias da instituição, sintetizadas a seguir.

\section{Modelo SENAI de prospecção, pesquisas para identificação de demandas e comitês técnicos setoriais}

A prospecção tecnológica e organizacional realizada pelo SENAI contribui para a competitividade das empresas e para a empregabilidade dos alunos, pois permite a identificação das tecnologias emergentes que serão utilizadas pelo parque industrial, num período aproximado de 10 anos, e possibilita analisar impactos no mundo do trabalho e da educação. Para realizar essas atividades, o SENAI dispõe de três Observatórios - Educacional, Tecnológico e do Trabalho, que realizam prospecções e analisam tendências que possibilitam antecipar ações de educação profissional e de assessoria técnica e tecnológica para as indústrias.

Tendo como base os procedimentos metodológicos para o desenvolvimento de pesquisas de mercado de trabalho, são elaborados estudos e análises sobre as necessidades específicas das empresas e da comunidade, sejam demandas por capacitação profissional, sejam por serviços tecnológicos decorrentes do processo de modernização tecnológica e organizacional das empresas. 


\section{Os cursos de graduação em tecnologia são atualmente as alternativas mais procuradas por aqueles que já estão no mercado de trabalho, mas querem e precisam se qualificar para manter a sua empregabilidade ou contribuir para sua ascensão profissional.}

A criação de Comitês Técnicos Setoriais é um forte instrumento utilizado pelo SENAI para aproximar a educação profissional das reais demandas do mundo produtivo. Integrados por representantes das empresas, dos trabalhadores e do meio acadêmico, além de especialistas em educação profissional, esses colegiados identificam as competências necessárias dos profissionais de cada setor industrial e definem os programas de formação mais adequados. Os currículos baseados nas competências e nos perfis profissionais proporcionam maior flexibilidade e modularização das atividades e têm assegurado alto nível de aceitação, pelas indústrias, dos técnicos formados pelo SENAI.

\section{A graduação em tecnologia}

A partir de 1996, as mudanças no ensino brasileiro foram estruturais e provocaram alterações significativas no contexto educacional brasileiro. A legislação promoveu a regulamentação da educação profissional, alterando a concepção de cursos técnicos e consolidando os cursos superiores de tecnologia, que tiveram um reforço substancial com a nova legislação.

Os cursos superiores de tecnologia estão articulados com o mercado de trabalho e a justificativa de sua implantação deve demonstrar a demanda de oportunidade de trabalho para o profissional que pretende formar. Enquanto os cursos de bacharelado são estruturados por meio da articulação entre a academia e o conhecimento, os cursos de tecnologia articulam-se com os eixos profissionais, com o conhecimento e com a prática. Esses cursos, além de uma perspectiva de formação diferenciada, representam uma oportunidade de qualificação para uma grande parcela da população brasileira que não consegue ter acesso à educação superior.

Os bacharelados reforçam o conhecimento teórico e acadêmico, propondo uma formação tradicional centrada no conhecimento científico. A formação de tecnólo- gos utiliza a prática como ferramenta para a construção do conhecimento. A formação do tecnólogo não está somente voltada para a prática, mas principalmente para o desenvolvimento de competências, objetivando mobilizar os conhecimentos, habilidades e atitudes na resolução de problemas, no desenvolvimento e difusão de tecnologias. Trata-se de uma formação mais dinâmica e prática, e que propõe profundidade, conhecimento focado e contextualizado, autonomia e educação continuada.

Os cursos de graduação em tecnologia são atualmente as alternativas mais procuradas por aqueles que já estão no mercado de trabalho, mas querem e precisam se qualificar para manter a sua empregabilidade ou contribuir para sua ascensão profissional. O ingresso no curso se dá por meio de processo seletivo, com as mesmas exigências legais para admissão em todos os cursos, de todas as instituições de educação superior no país, sob o monitoramento e controle do Ministério da Educação. Após a sua conclusão, o aluno pode prosseguir em cursos de pós-graduação, inclusive mestrado e doutorado, desde que, como nos demais cursos de graduação, o aluno atenda aos critérios estabelecidos pelo programa de pós-graduação (Catálogo Nacional de Cursos Superiores de Tecnologia - MEC, 2006).

Muitos colaboradores de empresas se inscrevem nos cursos de tecnologia para uma nova graduação. Encontram aí uma oportunidade de nova qualificação em competências mais específicas para as atividades em que atuam profissionalmente e onde se da ênfase à prática requerida nas empresas.

Uma questão antiga na educação brasileira é a pouca atenção e o baixo incentivo dispensados pelos governos à educação profissional técnica e tecnológica, gerando distorção na oferta de capital humano para as empresas. A maior destinação de recursos nessa área não só propiciará o aumento da taxa de retorno da educação como também possibilitará a redução das desigualdades educacional e econômica. A proporção de 
alunos matriculados em cursos superiores de tecnologia e seqüenciais ainda não atinge $10 \%$ da matrícula total no ensino superior. Constata-se uma reduzida oferta de cursos superiores de tecnologia e seqüenciais, diante da demanda do setor produtivo.

Para orientar a oferta de cursos de graduação em tecnologia, o Ministério da Educação, após exaustiva consulta a todos os setores da sociedade interessados no assunto, estabeleceu os parâmetros para a oferta desta modalidade de educação superior no país, por meio do Catálogo Nacional de Cursos Superiores de Tecnologia.

O Catálogo Nacional de Cursos Superiores de Tecnologia, lançado pelo Ministério da Educação em junho de 2006, é um importante instrumento produzido com a participação de toda a comunidade educacional. Constitui-se documento orientador para a oferta das graduações tecnológicas no Brasil.

O documento registra as denominações, sumário de perfil do egresso, carga horária mínima e infra-estrutura recomendada de 98 graduações tecnológicas organizadas em 10 eixos tecnológicos.

Figura 3. 0 catálogo reflete a diversidade presente no desenvolvimento tecnológico ${ }^{3}$

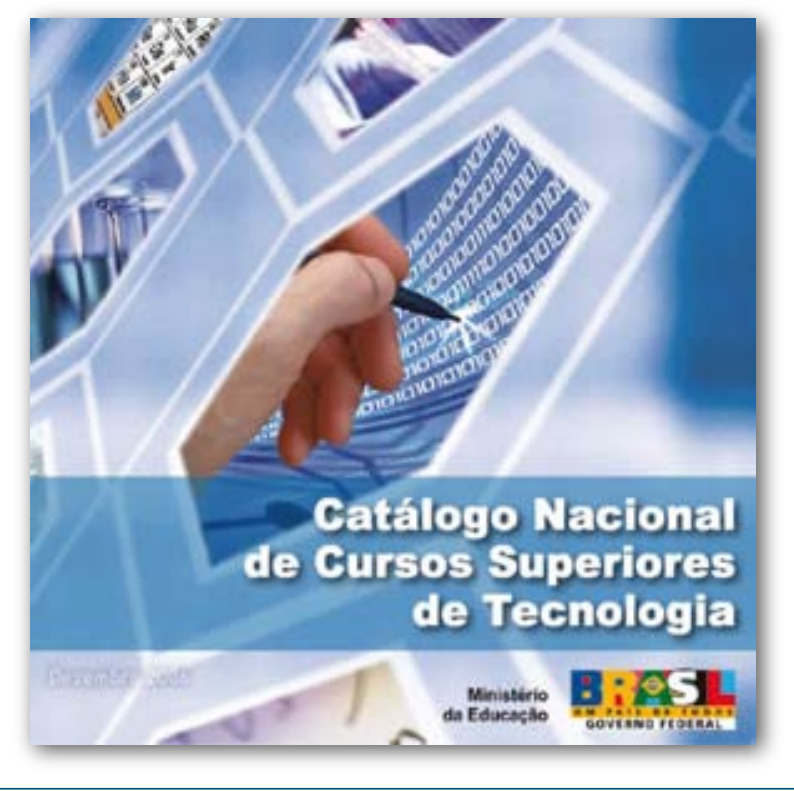

3. Disponível no sítio eletrônico do Ministério da Educação: www.mec.gov.br/setec.

\section{Considerações finais}

O SENAI percebeu, nos últimos anos, que deveria investir em uma modalidade de educação superior que atendesse às necessidades atuais do Brasil. Após realizar estudos de prospecção e de demandas por educação profissional e tecnológica, decidiu pela manifestação unânime de sua equipe técnica, reunindo profissionais de todos os Departamentos Regionais, submeter ao seu Conselho Nacional proposta de prioridade para a oferta de cursos de graduação e de pósgraduação em tecnologia, ao considerar sua participação na educação superior.

O Conselho Nacional do SENAI aprovou a proposta e, para manter a unidade de atuação na Rede SENAI, baixou resolução contendo as diretrizes para a educação superior, elaboradas e validadas, com participação de especialistas dos 27 Departamentos Regionais, apresentadas a seguir.

\section{Diretrizes da educação superior do SENAI}

1. A educação superior do SENAI constitui iniciativa dos Departamentos Regionais, observadas a legislação em vigor, as diretrizes institucionais, o compromisso com a inclusão social e o real interesse da indústria, da população e do país.

2. A oferta de cursos superiores deve atender à demanda comprovada da indústria, em complementação ao atendimento das redes públicas e privadas de educação superior, mantida a atuação prioritária na aprendizagem e na qualificação profissional de jovens e adultos.

3. Os cursos superiores oferecidos devem ser, preferencialmente, de educação profissional tecnológica de graduação e de pós-graduação.

4. A denominação dos estabelecimentos credenciados e as estratégias de divulgação dos cursos superiores devem conter, necessária e destacadamente, a marca SENAI.

5. Os cursos superiores devem ser viabilizados mediante o aproveitamento da capacidade 
instalada do SENAI, devendo ser auto-sustentáveis, observadas as exigências específicas do projeto pedagógico e da clientela desse nível de formação.

6. As parcerias com outras instituições de educação superior ou de pesquisa são consideradas oportunas e convenientes, desde que os custos, os benefícios e as responsabilidades das partes estejam claramente definidos em instrumento jurídico adequado que resguarde o equilíbrio das partes envolvidas e a imagem institucional, observando-se:

- o atendimento a demandas localizadas e por tempo determinado;

- a absorção e domínio de competências técnicas, administrativas e pedagógicas relacionadas à educação superior;

- a realização de pesquisas tecnológicas ou acadêmicas em que o SENAI e a indústria sejam campos privilegiados para as ações propostas.

7. Os cursos superiores deverão ser sistematicamente avaliados, tendo como referência padrões de excelência pedagógica e tecnológica, objetivando a melhoria contínua de seus processos acadêmicos e administrativos.

O interesse do SENAI pela educação profissional tecnológica de graduação e de pós-graduação é o reconhecimento pela precedência do desenvolvimento tecnológico em relação à produção científica, em termos de benefícios econômicos e sociais para o país, apoiando o desenvolvimento industrial e o aumento da competitividade da indústria nacional no contexto globalizado.

Os cursos de graduação tecnológica do $\mathrm{SENAI}^{4}$ são distribuídos em seis áreas de conhecimento, tendo maior destaque nas áreas de controle de processos industriais e produção industrial, como se pode ver:

\section{Educação superior no SENAI}

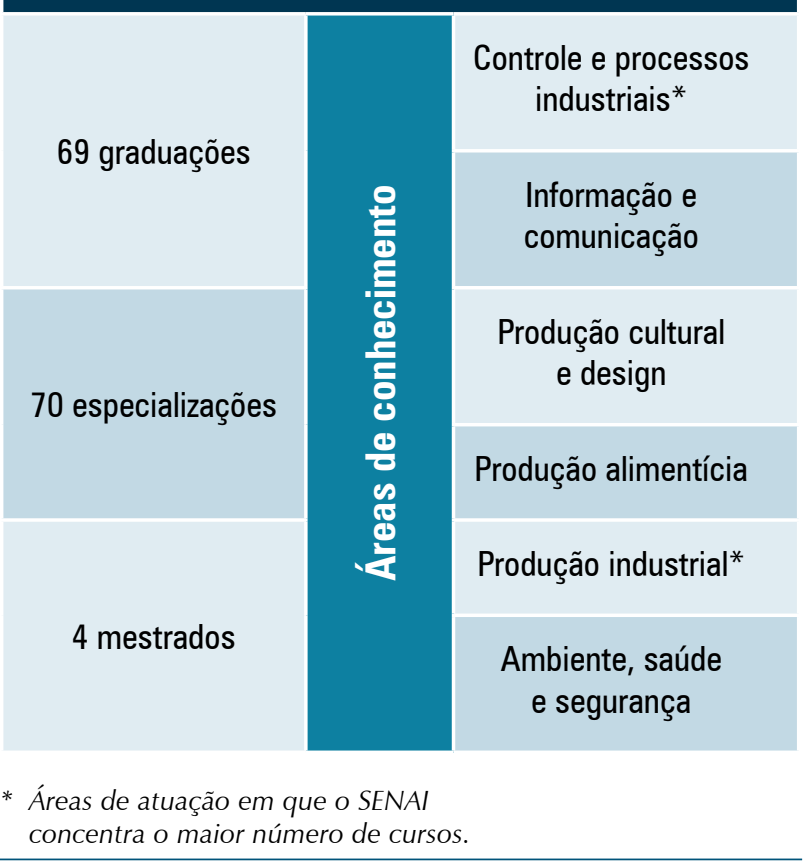

A oferta de educação superior pelo SENAI cresce em percentuais superiores às demais modalidades $\mathrm{e}$ níveis de educação profissional. Um fato merecedor de destaque tem sido a elevada taxa de inserção dos concluintes dos cursos de graduação em tecnologia nas empresas, superior a 95\%. Isso se deve à metodologia utilizada, desenvolvida e consolidada pelo SENAI, a partir de 1999. Todos os cursos superiores de tecnologia do SENAI são criados a partir da identificação de tendências e demandas comprovadas, com participação dos principais atores relacionados com o setor. As demandas e as tendências são traduzidas em termos de competências, habilidades, atitudes e valores que, por sua vez, orientam a elaboração do desenho curricular do curso.

Fundamentada na metodologia de formação por competências, cujos princípios são flexibilidade, contextualização, interdisciplinaridade, aprendizagem significativa, integração entre teoria e prática e avaliação, a proposta pedagógica utilizada pelo SENAI foi distinguida pela Associação Brasileira de Mantenedoras de

4. Informações sobre os cursos de graduação e pós-graduação em tecnologia oferecidos pelo SENAl estão disponíveis no sítio: www.senai.br. 
Ensino Superior - ABMES com o Prêmio Top Educacional Professor Mário Palmério 2006.

A formação de tecnólogos pelo SENAI estabelece um importante elo entre o mundo do trabalho e a instituição formadora. Os cursos oferecidos integram as competências laborais requeridas pelas empresas à preparação do profissional para uma realidade em cons- tantes mudanças que exigem formação continuada ao longo de sua atividade produtiva.

Observa-se, na educação tecnológica - graduação e pós-graduação - demandada pela indústria, a perspectiva de uma educação profissional ampliada, alinhada ao desenvolvimento industrial e à vertente de cidadania qualificada para a sua plena realização.

\section{- ALBERTO BORGES DE ARAUJO}

Bacharel em Direito pela Universidade Federal Fluminense, é mestre em Educação pela Universidade do Estado da Paraíba. Possui licenciatura em Pedagogia pela Faculdade de Educação, Ciências e Letras do Rio de Janeiro e especialização em Tecnologia Educacional pela Universidade do Estado do Rio de Janeiro.

\section{Referências}

ASSOCIAÇÃO BRASILEIRA DE MANTENEDORAS DE ENSINO SUPERIOR - ABMES. Prêmio Top Educacional Professor Mário Palmério 2006. Brasília: Associação Brasileira de Mantenedoras de Ensino Superior, 2007. 80 p. (Cadernos ABMES; 17).

BARROS, Waldemar de. SENAI: seu departamento da 4 a região. Rio de Janeiro - Estado da Guanabara: C.F.P. de Artes Gráficas do SENAI, 1974. 569 p.

BARONE, R. E. M. Formação profissional: uma contribuição para o debate brasileiro contemporâneo a partir da experiência internacional. Disponivel em: http://www.senac.br/INFORMATIVO/BTS/241/boltec241b.htm. Acesso em julho de 2007.

CONFEDERAÇÃO NACIONAL DA INDÚSTRIA. Mapa Estratégico da Indústria: 2007 - 2015. Brasília: CNI/DIREX, 2005.121 p.

CONFEDERAÇÃO NACIONAL DA INDÚSTRIA. Contribuição da indústria para a reforma da educação superior. Brasília: CNI/SESI/ SENAI/IEL. 2004. 48 p.

CONFEDERAÇÃO NACIONAL DA INDÚSTRIA. Crescimento. A visão da indústria. Brasília: CNI, 2006. 169 p.

DAHLMAN, Carl; FRISCHTAK, Cláudio. Tendências da indústria mundial: desafios para o Brasil. Brasília: CNI/DIREX, 2005. 46 p.

INSTITUTO EUVALDO LODI. NÚCLEO NACIONAL. Inova Engenharia - propostas para a modernização da educação em engenharia no Brasil. Brasília: IEL/CN/SENAI/DN, 2006. 103 p.

IPEA, Ministério do Planejamento, Orçamento e Gestão. Brasil, o estado de uma nação, mercado de trabalho, emprego e informalidade. Paulo Tafener, Editora, Rio de Janeiro, 2006.

Políticas sociais, acompanhamento e análise. Edição Especial, 13, Brasília/DF, Ed. IPEA, 2007.

. Inovações, padrões tecnológicos e desempenho das firmas industriais brasileiras, Brasília/DF, Ed. IPEA, 2005.

MONTEIRO NETO, Armando. O que a indústria brasileira espera das universidades. In: MORHY, Lauro (org.). A universidade em questão. Volume 1, Laboratório de Estudos do Futuro, Núcleo de Estudos sobre Ensino Superior da UnB/Nesub. Brasília, Editora Universidade de Brasília, 2003.

PORTO, Cláudio; RÉGNIER, Karla. O ensino superior no mundo e no Brasil - condicionantes, tendências e cenários para o horizonte 2003 - 2025. Uma abordagem exploratória. [S.I.: s.n.], 2003.

RANIERE, Nina Beatriz. Educação superior, direito e estado na Lei de Diretrizes e Bases (Lei no 9.394/96). São Paulo, Edusp/Fapesp, 2004.

RIVERA. C.; PETRONE, M. A. M. Educação profissional: amadorismo ou preconceito? A necessidade de uma política de longo prazo. Disponível em: http://www.humus.com.br/news_unhob.htm. Acesso em julho de 2007.

SCHWARTZMAN, Simon; CHRISTOPHE, Micheline. A sociedade do conhecimento e a educação tecnológica. Brasília: SENAI/DN, 2005. 109 p. (Série Estudos Educacionais; 2)

UNESCO. Fundamentos da nova educação. Cadernos Unesco/Brasil, Série Educação, Volume 5, 2003. . Ensino médio no século XXI. Cadernos Unesco/Brasil, Série Educação, Volume 4, 2001. 